\title{
INTERFACE E USABILIDADE NO LIVRO DIDÁTICO DIGITAL
}

\section{INTERFACE AND USABILITY IN THE DIGITAL TEXTBOOK}

Neusa de Oliveira Carneiro1, M.Sc.

Maria José Baldessar2 D.Sc.

(1) Universidade Federal de Santa Catarina

e-mail:neusacar@gmail.com

(2) Universidade Federal de Santa Catarina

e-mail:_mbaldessar@gmail.com

Palavras-chave: livro didático, livro didático digital, interface.

Este artigo analisa um livro didático digital (LDD), considerando conceitos de interface, usabilidade e navegação. Foi realizada uma análise descritiva do LDD Português 1 Pré-Vestibular, da editora Poliedro. Inicialmente são abordados conceitos relacionados a livro, livro digital, breve histórico e contexto do livro didático e o aparecimento deste na forma digital, com ênfase na realidade brasileira. A segunda parte descreve o objeto de estudo, analisa a interface e mostra os resultados e discussões. Considerando as especificidades do LDD são necessários critérios diferenciados para análise, que contemplem suas características distintivas e sua finalidade didática, de maneira a aproveitar as possibilidades que o meio digital oferece.

Key-words: textbook, digital textbook, interface.

This article analyzes a digital textbook (DT), considering concepts of interface, usability and navigation. A descriptive analysis of the digital textbook Portuguese 1 Pré-Vestibular, from the Poliedro publishing house. Initially, concepts related to the book, digital book, brief history and context of the didactic book and the appearance of it in digital form, with emphasis on the Brazilian reality, are approached. The second part describes the object of study, analyzes the interface and shows the results and discussions. Considering the specificities of the DT, different criteria are required for analysis, considering their distinctive characteristics and their didactic purpose, in order to take advantage of the possibilities offered by the digital medium. 


\section{$16^{\circ}$ \\ ERGODESIGN USIHC CINAHPA}

\section{Introdução}

O surgimento do livro está ligado ao registro de informações, inicialmente com fins comerciais, ao longo do tempo passou a ser utilizado em outros contextos, inclusive na educação. $\mathrm{O}$ aperfeiçoamento do papel e a invenção da imprensa trouxeram portabilidade, diminuíram os custos e facilitaram o acesso, com isto, o livro popularizou-se e se tornou cada vez mais comum nas escolas e universidades. Este processo marca o aparecimento do livro didático, usado primeiro pelos professores e mais tarde adotado pelos estudantes.

O livro didático é organizado com objetivos e intencionalidade de aprendizagem, engloba recursos como textos, imagens, tabelas, gráficos, indicações de outras leituras, peças teatrais, filmes e músicas. O processo de produção envolve uma complexidade de fatores, com a interferência de interesses do mundo editorial, educacional, político e econômico.

$\mathrm{O}$ aprimoramento das tecnologias digitais propiciou o surgimento do livro digital, que altera o aspecto material do objeto livro, incorpora novos recursos e suscita discussões sobre a própria definição do que é livro. Antes do livro digital, não havia separação entre conteúdo e suporte. O livro impresso era um objeto material, palpável e nuclear, o objeto físico e o texto constituíam uma unidade. No livro digital o texto está codificado em bits e depende de um software ou dispositivo específico para leitura. A passagem do livro impresso para o digital promove a ruptura entre texto e suporte, aparecem características e recursos diferentes, novas apropriações e experiências de leitura e retenção do conteúdo.

A organização do mercado editorial está implícita nas definições do livro, com a separação da cadeia de produção, comercialização e distribuição e funções de autor, editor, distribuidor e revendedor. O modelo de negócios desse mercado é baseado na cultura tradicional do impresso, com separação bem definida dos processos, funções, remunerações e prazos. A organização da cadeia produtiva do livro está consolidada e é refratária a inovações, incorporadas lentamente e com resistência. $16^{\circ}$ Ergodesign - Congresso Internacional de Ergonomia e Usabilidade de Interfaces Humano Tecnológica: Produto, Informações Ambientes Construídos e Transporte

$16^{\circ}$ USIHC - Congresso Internacional de Ergonomia e Usabilidade de Interfaces Humano Computador

CINAHPA | 2017 - Congresso Internacional de Ambientes Hipermídia para Aprendizagem.

O aparecimento do livro digital promove mudanças radicais neste ambiente, gerando conflitos de natureza econômica e cultural, que vão desde a fusão, supressão e aparecimento de novas funções, com perfil diferenciado e dependente do domínio das tecnologias da informação e comunicação, até novos fluxos de produção, distribuição, uso, remuneração, autoria e formato.

$\mathrm{Na}$ forma digital, o livro pode ser difundido mais amplamente, são adicionadas possibilidades interativas do meio digital, com novos potenciais e possibilidades de leitura. Também aparecem desafios, como o acesso das populações mais pobres a tecnologia, superficialidade e distrações da leitura no meio digital.

O livro digital é uma nova mídia em processo de formação, cuja estética e organização baseia-se no livro impresso, porém, à medida que amadurece, tende a criar seu próprio padrão, com características diferenciadas, numa relação dinâmica com o meio digital e seu público, cujas interações produzem alterações recíprocas que moldam o novo meio e alteram o perfil e os hábitos do leitor/usuário.

As possibilidades do livro digital podem estar presentes também no livro didático digital (a partir de agora LDD), que, no Brasil, aparece em função das exigências do Plano Nacional do Livro Didático, a partir dos editais de 2013. Porém, os editais não trazem definições claras a respeito das características e recursos que o LDD deve possuir.

Outros países também passam por enfrentamentos e choques entre a cultura do impresso e do digital e entre opções abertas e proprietárias. O objeto LDD é recente, não há um conceito definido e amplamente aceito e, assim como outros produtos tecnológicos, o mercado do LDD desperta competição e gera diversidade de padrões, causando confusão conceitual e dificultando análises e comparações técnicas. Além disto, os critérios de análise variam de acordo com a área de estudos.

Este trabalho visa analisar a interface, usabilidade e navegação do LDD Português 1 Pré-Vestibular, da editora Poliedro, destinado ao Ensino Médio. Parte-se de um breve resgate histórico sobre o livro didático no Brasil, aprofunda-se a discussão sobre 


\section{$16^{\circ}$ \\ ERGODESIGN USIHC CINAHPA}

o LDD e analisa-se um exemplar.

Buscou-se delimitar os conceitos que envolvem o LDD, verificar se os critérios da usabilidade e navegação podem ser utilizados para avaliá-lo e desta forma contribuir para melhorar o desenvolvimento de interfaces que facilitem a experiência dos estudantes e favoreçam a aprendizagem e a difusão do conhecimento.

\section{Contexto e problemática}

$\mathrm{O}$ ambiente digital oferece novas possibilidade e desafios, como todo novo meio altera o sistema estabelecido e precisa produzir sua própria estética e modo de ser utilizado. Suas características exigem interfaces mais fluidas e adaptáveis a diferentes contextos de uso e suportes.

O texto no formato digital populariza-se em função dos avanços tecnológicos, na web multiplicam-se iniciativas de autoria, mixagem e autopublicação, os aplicativos e dispositivos eletrônicos de leitura tornam-se mais amigáveis e oferecem novos recursos, tornando a leitura mais fácil, interativa e multimidiática.

O livro digital é uma das expressões do texto digital e, pode ser considerado uma nova mídia, em processo de formação, tanto em termos conceituais quanto funcionais. $\mathrm{O}$ livro digital altera significativamente a forma de organizar o conteúdo (SANTAELLA, 2013), pois o ambiente digital oferece novas possibilidades e características diferenciadas, que alteram a forma de organizar, ler e reter o conteúdo. Tais características podem ter grande potencial de uso na educação, facilitando a apreensão e difusão do conhecimento.

Segundo Oliveira (2011, p. 6), "livros impressos e e-books se diferenciam não somente pelo tipo de suporte que os sustenta, mas principalmente pelo modo que configuram as interfaces de leitura que, em sua materialidade, também agregam significado."

Considerando que estão envolvidos na produção e distribuição do livro digital tanto editoras quanto empresas de tecnologia, que passam a ser concorrentes, há uma disputa pela tecnologia e padrões usados, seja no formato de arquivo (pdf, epub, mobi, html e outros), nos aplicativos de $16^{\circ}$ Ergodesign - Congresso Internacional de Ergonomia e Usabilidade de Interfaces Humano Tecnológica: Produto, Informações Ambientes Construídos e Transporte

$16^{\circ}$ USIHC - Congresso Internacional de Ergonomia e Usabilidade de Interfaces Humano Computador

CINAHPA | 2017 - Congresso Internacional de Ambientes Hipermídia para Aprendizagem.

leitura, ou nos dispositivos eletrônicos de leitura (e-readers).

Há dificuldade em nomear e definir o livro digital, autores e organizações possuem seus próprios conceitos, que são controversos e díspares. Os nomes são vários: livro digital; livro eletrônico ou e-book. Também variam os equipamentos de leitura, que podem ser o computador, notebook, tablet, smartphone ou dispositivo eletrônico específico, como o Kindle, Kobo, Lev e Nook. Como os dispositivos foram desenvolvidos por empresas diferentes, cada uma criou formatos de arquivo específico e padrões fechados que não permitem o intercâmbio e a utilização dos livros digitais em diferentes dispositivos.

Ao discutir sobre o livro digital e o LDD é inevitável defrontar-se com novos modelos de negócio e forças determinantes do mercado que buscam garantir seu espaço, o que evidencia o acirramento do conflito entre a cultura tradicional do impresso e a cultura do meio digital.

O desenvolvimento e aperfeiçoamento do livro digital viabiliza sua adoção na educação, na forma de livros didáticos, que, de acordo com o Guia Livres (2005, p.7) "são todas as obras cuja intenção original é explicitamente voltada para o uso pedagógico e esta intenção é manifestada pelo autor ou editor". Para Munakata (2012, p. 58) didático "é o livro produzido para fins educacionais, visando principalmente ao público escolar."

O livro didático é de natureza complexa e, de acordo com Choppin (2004), envolve uma diversidade de agentes, multiplicidade de funções e coexistência com outros suportes educativos. Esta complexidade surge na sua origem, situada no "cruzamento de três gêneros que participam, cada um a seu modo, do processo educativo" e que são "a literatura religiosa de onde se origina a literatura escolar", "a literatura didática, técnica ou profissional que se apossou progressivamente da instituição escolar" e "a literatura 'de lazer"'(CHOPPIN, 2004, p. 552).

De acordo com Munakata (2012, p. 58) pode se dizer que o surgimento do livro didático ocorre "a partir do século XIII" período em que havia "uma modalidade de livros manuscritos, em estreita 


\section{$16^{\circ}$ \\ ERGODESIGN USIHC CINAHPA}

associação com a expansão das universidades e de sua clientela." Nesta época, anterior a imprensa, já existia uma fatia de mercado dedicada aos livros didáticos, cujos clientes eram os universitários. É a partir da constituição dos Estados nacionais e da formalização dos sistemas de ensino que este mercado cresce expressivamente e "o livro escolar torna-se um símbolo da soberania nacional" (CHOPPIN, 2004, p. 555).

No Brasil, os primeiros livros didáticos foram produzidos em 1810, com a instalação da Imprensa Régia (KANASHIRO, 2006). Em 1874, o ensino primário tornou-se obrigatório em São Paulo e ampliaram-se o número de escolas, com isto, surge a demanda por livros para as escolas.

Posteriormente, esta necessidade deu origem a "um mercado que até os dias atuais assegura a solidez das editoras que se dedicam a esse segmento" (ROSA, 2009, p. 87).

No Brasil, o governo federal compra e distribui gratuitamente livros didáticos para alunos e professores da rede pública de ensino, por meio do Programa Nacional de Livros Didáticos (PNLD). O edital com as especificações para os livros é lançado com antecedência de dois anos pelo Ministério da Educação (MEC). O PNLD incorporou a partir de 2015 o livro digital (BRASIL, 2013), demonstrando a percepção da importância desta mídia, bastante disseminada em outros ambientes, porém pouco utilizada na escola. Neste edital, o LDD é apresentado como um recurso capaz de substituir os livros didáticos no formato tradicional, com utilização de objetos educacionais como tutoriais, jogos educacionais, animações, vídeos, áudios, infográficos, páginas da web e outros elementos.

O edital de 2015 previa a inclusão de obras multimídia, com o mesmo conteúdo do livro impresso. A ideia de livro digital é baseada no impresso, com adição de recursos como vídeos, animações, simuladores, imagens, jogos e textos. Em 2016, o edital prevê que os livros digitais sejam utilizados sem necessidade de conexão permanente à Internet, exceto no primeiro acesso. Os editais do PNLD não oferecem uma definição clara a respeito das características e recursos que o LDD pode ou deve possuir, uma vez que estão focados na versão impressa. $16^{\circ}$ Ergodesign - Congresso Internacional de Ergonomia e Usabilidade de Interfaces Humano Tecnológica: Produto, Informações Ambientes Construídos e Transporte

$16^{\circ}$ USIHC - Congresso Internacional de Ergonomia e Usabilidade de Interfaces Humano Computador

CINAHPA | 2017 - Congresso Internacional de Ambientes Hipermídia para Aprendizagem.

Canavilhas (2014) identifica as características do meio digital: interatividade, hipertextualidade, multimidialidade, personalização, memória, atualização contínua ou instantaneidade e ubiquidade. Sendo o LDD uma mídia deste meio, é desejável que possua tais características. Para tanto, é necessário que as pesquisas na área avancem, de forma a responder as necessidades da sociedade e aproveitar este potencial tecnológico para a educação.

O estudo sobre o LDD é recente e pouco explorado, de modo que está aberto a novas interpretações. Esta discussão exige aprofundamento teórico e envolve a dimensão econômica, jurídica, cultural, social e política, num entrelaçamento complexo de atores do mercado editorial, professores, alunos e empresas de produção e distribuição de conteúdos digitais educacionais.

O LDD oferece um novo contexto que permite abordar a contribuição que a tecnologia pode oferecer a educação e permite delinear as características desejáveis para o LDD como artefato digital. Neste sentido, seu estudo envolve as possibilidades surgidas com o desenvolvimento das tecnologias da informação e comunicação, novos formatos e potenciais de leitura com maior participação do leitor e opção de fazer novos percursos.

Desta maneira, tem se um ambiente propício a experimentação teórica e prática, para se estabelecer classificações, critérios e padrões que possam atender às necessidades de professores $\mathrm{e}$ estudantes e equalizar os conflitos e desafios emergentes, de natureza cultural, social, econômica e política.

\section{A interface, usabilidade e navegação}

A interface define como a informação é organizada e como o usuário/leitor interage com ela, sendo assim, facilita a interação entre o usuário e o sistema ou dispositivo. De acordo com DE SOUZA et al. (1999, p. 3), a interface "é a parte de um artefato que permite a um usuário controlar $\mathrm{e}$ avaliar o funcionamento deste artefato através de dispositivos sensíveis às suas ações e capazes de 


\section{$16^{\circ}$ \\ ERGODESIGN USIHC CINAHPA}

$16^{\circ}$ Ergodesign - Congresso Internacional de Ergonomia e Usabilidade de Interfaces Humano Tecnológica: Produto, Informações Ambientes Construídos e Transporte

$16^{\circ}$ USIHC - Congresso Internacional de Ergonomia e Usabilidade de Interfaces Humano Computador

CINAHPA | 2017 - Congresso Internacional de Ambientes Hipermídia para Aprendizagem. estimular sua percepção", também é utilizada para referir-se "àquilo que interliga dois sistemas". Para os autores, a interface entre usuário e sistemas computacionais exige esforço cognitivo para interpretar as informações processadas pelo sistema. Coelho (2008), entende a interface como "o desdobramento da comunicação do homem com algum sistema, máquina, ambiente, etc."

A norma NBR 9241, baseada na ISO 9241 (International Organization for Standardization), trata dos requisitos para trabalho com computadores, o item 11 aborda usabilidade e a define como "medida na qual um produto pode ser usado por usuários específicos para alcançar objetivos específicos com eficácia, eficiência e satisfação em um contexto específico de uso." (ABNT, 2011, p.3). Neste sentido, é importante considerar a usabilidade no projeto de produtos, pois ela pode oferecer uma medida da capacidade dos usuários em trabalhar de modo eficaz, efetivo e com satisfação.

A usabilidade compõe-se de aspectos objetivos, como a produtividade, facilidade de uso e de aprendizado, e subjetivos, como a satisfação do usuário na experiência com a interface. Segundo Coelho (2008, p. 228), a usabilidade trata da "adequação entre o produto e as tarefas a cujo desempenho se destina, da adequação com o usuário que o utilizará e da adequação ao contexto em que será usado".

A usabilidade determina a eficácia, eficiência, segurança, utilidade, facilidade de aprender e de lembrar como usar uma interface. Quanto mais fácil de usar menor será o tempo necessário para aprender a usá-la. Assim, para Preece, Rogers e Sharp, (2013, p. 18) a "usabilidade visa assegurar que produtos interativos sejam fáceis de aprender e usar, eficazes e agradáveis", tudo isto na perspectiva do usuário, leitor ou de quem vai usar o produto, serviço ou sistema. As autoras explicam que há critérios de usabilidade para aferir a eficiência (tempo gasto para completar uma tarefa), capacidade de aprendizado (tempo para aprender uma tarefa), facilidade de lembrar como usar (número de erros cometidos ao realizar uma tarefa) que "podem fornecer indicadores quantitativos" sobre a produtividade, porém, não é possível medir objetivamente a qualidade da experiência do usuário.
A navegação "é um processo de movimento entre os nós de um espaço informacional" e seu conceito "envolve tanto o aprendizado sintático - mais ligado ao nível operacional, focado no deslocamento, independente do conteúdo, quanto o aprendizado semântico - relacionado ao nível funcional, que auxilia na integração entre diferentes informações" (PORTUGAL, 2013, s.p.).

Para Kalbach (2009, p.21) "a navegação tem um papel fundamental em moldar nossas experiências na web" ao prover "acesso à informação de uma forma que melhora o entendimento" e "colabora para a credibilidade geral de um site". Fornece orientação, visto que o usuário precisa saber onde está, o que há ali e para onde pode ir. Neste sentido, ela trata do significado do conteúdo e ajuda a definir o contexto, criando coerência.

A "navegação bem projetada e fácil de ser usada é importante para estabelecer credibilidade, autoridade e confiança" (KALBACH, 2009, p. 36). É por meio da navegação que o usuário pode acessar a informação e sentir-se satisfeito ou frustrado em relação ao atendimento ou não de suas necessidades.

Portugal (2013, s.p.) aponta que "os componentes de navegação como menus, setas, nós de navegação, hipertextos, imagens etc. podem ser considerados um sistema" cujos objetivos são: "promover a orientação local e global dentro do próprio sistema; permitir o deslocamento entre os nós de navegação" e "preencher as necessidades humanas de autonomia, competência, estimulação".

A navegação implica o deslocamento de um ponto ao outro em um ambiente, software ou produto hipermídia. Assim, planejar a navegação significa estabelecer acesso ao conteúdo por meio de links cuja coerência permita ao usuário/leitor localizarse, saber como retornar e verificar o caminho percorrido. Os princípios de navegação orientam para que ela seja balanceada, consistente e forneça indicação clara de onde o usuário está e formas de conduzi-lo para onde quer ir, sem dificuldades e esforço com a informação.

O layout pode facilitar a navegação e a leitura, pois diz respeito a organização do texto e demais elementos na página e visa simplificar a 


\section{$16^{\circ}$ \\ ERGODESIGN USIHC CINAHPA}

compreensão das informações. Na área de design gráfico as técnicas empregadas envolvem proximidade e alinhamento, simetria e balanceamento, escala e proporção. As cores e tipos adequados podem tornar a leitura mais agradável e atrativa, melhorar a legibilidade e oferecer uma identidade ao livro. A consistência de cores e tipos facilita a organização e localização do leitor/usuário.

\section{Abordagem metodológica}

Este trabalho utiliza a abordagem qualitativa e envolve uma pesquisa aplicada, na qual foi analisado o livro didático digital Português 1 PréVestibular da Editora Poliedro, em relação a interface, usabilidade e navegação. Para isto, foram analisados os recursos e mídias disponíveis no livro.

Para a análise descritiva, acessou-se o LDD e foram utilizados todos os recursos oferecidos. A partir disto, estes foram comparados com o que preceitua a literatura sobre ambientes e sistemas digitais. Em relação a usabilidade, foram utilizadas as definições da norma NBR 9241-11, para a interface e navegação utilizou-se conceito dos autores citados.

Os critérios de análise permitiram verificar se o LDD atende aos requisitos deste ambiente e obter elementos que proporcionem conhecer melhor o objeto e suas possibilidades para proporcionar uma experiência de uso fácil, produtiva, agradável e que contribua para a aprendizagem dos estudantes.

A busca pelo LDD para análise foi realizada na página web de editoras que constam no PNLD, porém, as quatro editoras consultadas não disponibilizam exemplar gratuito. Para se obter acesso a versão digital é necessário possuir a impressa, que contém o código de acesso e senha ou obtê-los pelo cadastro criado para o estudante ao adquirir os exemplares impressos.

Este processo dificultou o acesso, depois de tentativas diversas conseguiu-se o acesso à versão digital e impressa para análise e comparações. O livro escolhido está disponível no perfil do estudante, na página web da editora Poliedro. $16^{\circ}$ Ergodesign - Congresso Internacional de Ergonomia e Usabilidade de Interfaces Humano Tecnológica: Produto, Informações Ambientes Construídos e Transporte

$16^{\circ}$ USIHC - Congresso Internacional de Ergonomia e Usabilidade de Interfaces Humano Computador

CINAHPA | 2017 - Congresso Internacional de Ambientes Hipermídia para Aprendizagem.

\section{Apresentação do objeto de análise}

O LDD analisado foi "Português 1 Pré-Vestibular", para o terceiro ano do Ensino Médio, escrito por Renato Gomes de Carvalho e Esther Pereira Silveira Rosado. Publicado pelo Sistema de ensino Poliedro em 2015, está disponível para os estudantes que adquirem a versão impressa. Este livro é utilizado em escolas da rede particular. Pode ser acessado via internet pelo Portal Edros (https://portal.p4ed.com/) ou baixar o aplicativo em computadores, tablets e smartphones Android e IOS.

Para que seja instalado no equipamento do estudante (computador em versão para Windows, Linux, Mac OS, tablet ou smartphone Android e IOS), cada LDD requer um download inicial, mesmo assim, para acessá-lo é preciso fazer login. O LDD só pode ser utilizado em um dispositivo por vez, para usar em outro equipamento é necessário liberar o equipamento e repetir a instalação.

\section{Funcionalidades}

Para a análise foi utilizado o acesso web do portal do LDD e também baixou-se o aplicativo, num notebook equipado com processador Intel Core i5 de 2,2 giga-hertz, HD de 1 terabyte, 8 gigabytes de memória, tela de 14 polegadas com resolução de 1366x768 pixels e sistema operacional Windows 10 Home, sem opção de touchscreen.

A versão digital do livro é igual a impressa, com sequência de leitura semelhante ao livro impresso: capa, sumário, entrada de capítulo e páginas internas. A orientação da página é na vertical (retrato) e o sentido de leitura é na horizontal. A página é composta por duas colunas de texto justificadas, com margens laterais simétricas. A tipografia segue o mesmo padrão do livro impresso, as margens laterais são de tamanho reduzido, com isto, a tela fica sobrecarregada de texto reduzindo a legibilidade e a leiturabilidade. $\mathrm{O}$ contraste do texto com o fundo é equilibrado, mesmo com a utilização de cores nos subtítulos. 
$16^{\circ}$ USIHC - Congresso Internacional de Ergonomia e Usabilidade de Interfaces Humano Computador

CINAHPA | 2017 - Congresso Internacional de Ambientes Hipermídia para Aprendizagem.

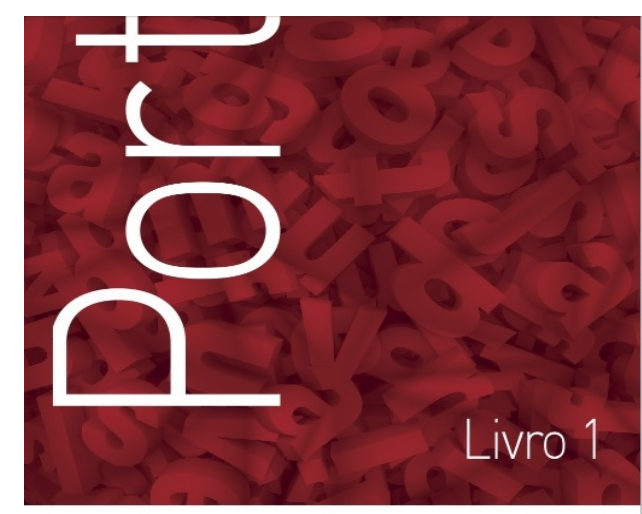

POLIEDRO

Figura 1 - Capa do LDD (captura de tela pelas autoras)

As opções de controle aparecem em botões divididos em dois menus, um na parte superior e outro na parte inferior da tela. São exibidas ferramentas com as opções de ajuste do tamanho, pesquisa no texto, adicionar anotações e informações sobre a localização no texto. $\mathrm{O}$ sumário é exibido no menu lateral à direita.

Os menus horizontais exibem as opções disponíveis e são mostrados quando se clica próximo aos limites superior e inferior da tela. No menu superior, à esquerda há o ícone para voltar a página inicial do portal, o título do LDD no centro e os botões Caderno de anotações, Adicionar anotações e Buscar no livro, à direita. O ícone para voltar é intuitivo, porém, o primeiro dos três botões do lado direito não é. Para adicionar anotações há um ícone em forma de lápis e na busca uma lupa, imagens comuns em páginas web e dispositivos como smartphones, que atendem aos requisitos da usabilidade, pois, são fáceis de aprender, usar e de lembrar como se usa. A aparência dos ícones poderia ser melhorada, pois parecem ícones de página web mais antigas.

No menu inferior aparece, à esquerda, o número da página e o título do capítulo ou seção em que se está posicionado, à direita estão os botões que permitem a visualização como página ou como livro. Na opção página pode se ver uma página por vez e na opção livro, duas páginas, como se fosse um livro impresso aberto. Esse recurso é explorado inclusive em editores de texto e favorece o aprendizado da interface.

Há um botão para abrir/fechar miniaturas das páginas do livro, ao ser clicado aparecem miniaturas das páginas do livro na parte inferior da tela, sobrepostas à página em que se está navegando. Ao clicar em uma das páginas em miniatura, é possível abri-la. Há ainda o botão Sumário, que abre uma barra na lateral esquerda com o título do LDD, opção de pesquisa para navegar pelas páginas e o sumário do livro. Ao clicar em qualquer item do sumário, é possível abri-lo. O menu inferior fornece orientação sobre a localização do leitor no livro, desta forma atende aos quesitos de navegação ao informar onde o leitor está. Os botões Sumário e o de busca permitem navegação não-linear pelo livro.

No menu superior, a função "Marcações e Anotações" permite que sejam feitas anotações, marcações, comentários e destaques no livro. Pode-se selecionar o tipo de marcação como desenhar à mão livre ou com as formas prédefinidas, inserir lembrete, anotação ou marcar texto com diferentes cores e formas. Depois de salvas, as marcações podem ser acessadas com a função "Caderno de Anotações", que possibilita visualizá-las resumidamente em uma janela, com a opção de navegar entre as anotações, organizá-las por tipo, vê-las na página do LDD ou apagá-las.

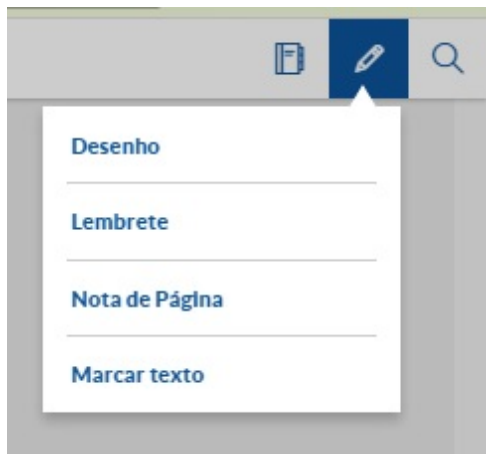

Figura 2 - Função Marcação (captura de tela pelas autoras) 


\section{$16^{\circ}$ \\ ERGODESIGN USIHC CINAHPA}

$16^{\circ}$ Ergodesign - Congresso Internacional de Ergonomia e Usabilidade de Interfaces Humano Tecnológica: Produto, Informações Ambientes Construídos e Transporte

$16^{\circ}$ USIHC - Congresso Internacional de Ergonomia e Usabilidade de Interfaces Humano Computador

CINAHPA | 2017 - Congresso Internacional de Ambientes Hipermídia para Aprendizagem.
A função "Procura" oferece a pesquisa por palavra ou frase e facilita a navegação mais rápida e nãolinear pelo conteúdo do LDD.

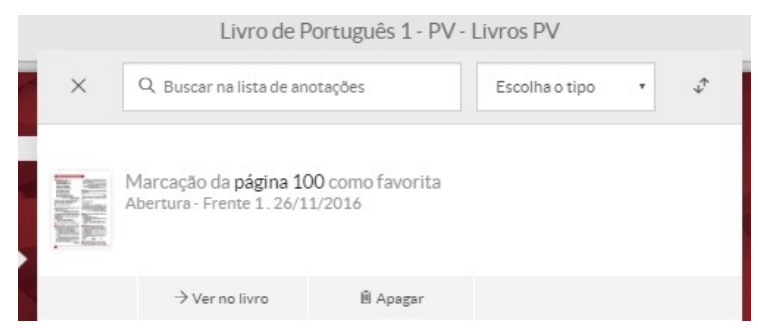

Figura 3 - Função Procura (captura de tela pelas autoras)

Há um sumário do livro na lateral direita, que permite ver a organização dos capítulos e navegar por páginas selecionadas, para visualizar uma miniatura das páginas há um botão no menu inferior.

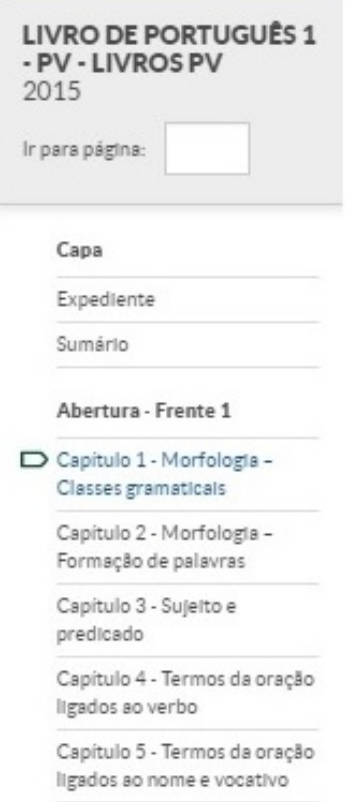

Figura 4 - Sumário do LDD (captura de tela pelas autoras)

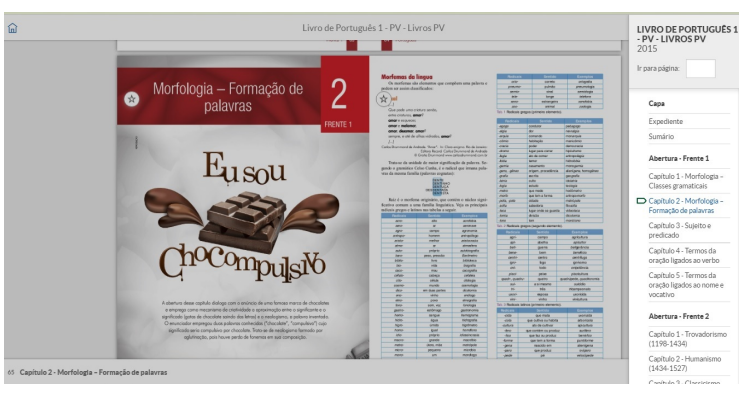

Figura 5 - Página do LDD com Sumário lateral (captura de tela pelas autoras)

Os hiperlinks internos (direcionamento para outras páginas ou seções do livro) foram utilizados somente no menu do Sumário e nas miniaturas, este recurso poderia ser melhor explorado no corpo do LDD.

Recursos como áudio e vídeo não estão disponíveis. Ao final de cada capítulo há dois blocos de exercícios, um na cor lilás e outro em azul com questões propostas por vestibulares de universidades brasileiras. São oferecidos textos complementares com fundo em amarelo-claro, um resumo do capítulo, em fundo verde-claro. $\mathrm{O}$ tópico "Quer saber mais" oferece dicas de livros, sites, filme, teatro e música, porém os links não são clicáveis. Há ainda exercícios complementares indicados por uma tarja vermelha no título.

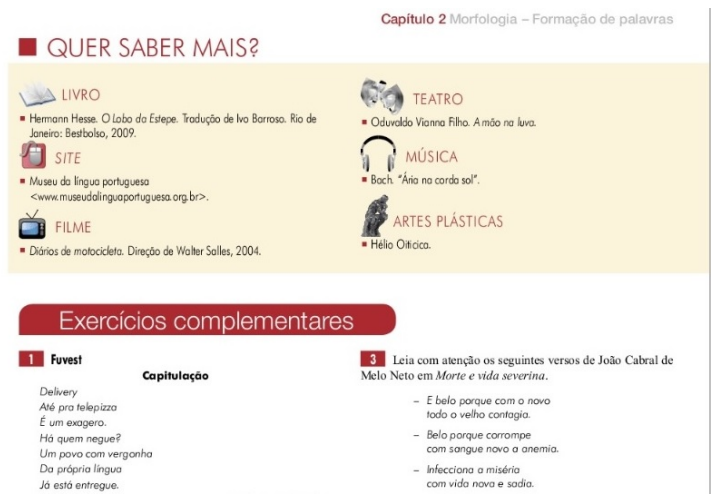

Figura 6 - Exercícios e recursos complementares do LDD (captura de tela pelas autoras) 


\section{$16^{\circ}$ \\ ERGODESIGN USIHC CINAHPA}

$16^{\circ}$ Ergodesign - Congresso Internacional de Ergonomia e Usabilidade de Interfaces Humano Tecnológica: Produto, Informações Ambientes Construídos e Transporte

$16^{\circ}$ USIHC - Congresso Internacional de Ergonomia e Usabilidade de Interfaces Humano Computador

CINAHPA | 2017 - Congresso Internacional de Ambientes Hipermídia para Aprendizagem.
O LDD não oferece instruções sobre como navegar nele, estas constam no manual, que pode ser baixado do portal, em formato pdf. É desejável que a interface do LDD seja intuitiva e facilite o uso, fornecendo pistas de como navegar e utilizar os recursos disponíveis.

O cuidado em desenvolver uma navegação eficiente é determinante para o sucesso de livros digitais, sejam didáticos ou não. Saber utilizar os recursos do meio digital e facilitar a navegação em diferentes plataformas ajuda a melhorar a experiência do leitor e pode ser um diferencial importante na decisão de escolha e leitura. No caso do LDD, pode facilitar a aprendizagem e assimilação do conteúdo pelos alunos.

A interface a usabilidade não são bem desenvolvidas no LDD. Considerando as definições da NBR 9241-11, em que a eficácia é a "acurácia e completude com as quais usuários alcançam objetivos específicos", a precisão para alcançar o objetivo de utilizar o LDD fica a desejar, pois, além do esforço em aprender o conteúdo do livro, há também uma sobrecarga cognitiva no aprendizado para usar o LDD. Em relação a eficiência, definida pela norma como os "recursos gastos em relação à acurácia e abrangência com as quais usuários atingem objetivos" o LDD analisado é pouco eficaz, pois demanda muitos cliques, esforço cognitivo e seu uso requer mais tempo do que seria desejável.

A satisfação, entendida como "ausência do desconforto e presença de atitudes positivas para com o uso de um produto", foi baixa e sente-se que o produto não incorpora recursos que facilitem a navegação.

O contexto de uso envolveu um notebook, sem recurso de touchscreen, o que pode diminuir a satisfação e a eficácia. Entretanto, o projeto não está suficientemente maduro e não contempla adequadamente características que podem facilitar o uso, como clicar com o mouse para folhear as páginas, que confere sensação de leveza e mantém um comportamento de leitura frequente no livro impresso. Outro recurso ausente no LDD e comum em livros digitais é guardar a página em que $o$ leitor parou.

O adequado planejamento da navegação contribui para experiências agradáveis, facilita o acesso à informação, melhora o entendimento, diminui o tempo de aprendizagem de uso do LDD e gera credibilidade. Ao fornecer orientação para o usuário, este saberá onde está, o que pode fazer e para onde pode ir. Isto ajuda a definir o contexto e provê significado ao conteúdo, algo imprescindível no LDD, que tem uma função didática.

Mesmo não sendo intuitiva a navegação oferece facilidade de aprender e de lembrar como se usa, porém, poderia exigir menos esforço cognitivo e cliques. Para assegurar que o LDD seja fácil de aprender e usar, eficaz e agradável poderiam ser adotados no projeto os critérios de usabilidade para aferir a eficiência (tempo gasto para completar uma tarefa), capacidade de aprendizado (tempo para aprender uma tarefa), facilidade de lembrar como usar (número de erros cometidos ao realizar uma tarefa) que são usados em outras plataformas, como páginas web e games.

O design visual, imediatamente perceptível, com texto legível (cores, fontes e constaste), ícones adequados para representar sua função, destaque diferenciado a partes importantes é equilibrado, porém pode ser melhorado, em especial nas margens. Os componentes essenciais do design visual envolvem a tipografia, malha gráfica, grid e o esquema de cores, que devem ser capazes de comunicar com clareza.

\section{Resultados e discussão}

As abordagens e metodologias sobre usabilidade e navegação estão difundidas na Interação HumanoComputador e são maduras no desenvolvimento de interfaces para sistemas computacionais e mais recentemente são utilizadas no projeto de páginas web, porém, considerando que o LDD não se enquadra nesta categoria, os critérios podem ser parcialmente aplicados.

O LDD é uma mídia digital recente, que herda padrões e modelos do livro impresso e ao mesmo tempo espera-se que incorpore funcionalidades do meio digital. Porém, no exemplar analisado, a interface e a usabilidade deixam a desejar. A eficácia, eficiência e satisfação podem ser melhoradas com a utilização de recursos simples e 


\section{$16^{\circ}$ \\ ERGODESIGN USIHC CINAHPA}

que estão disponíveis em livros digitais, como folhear as páginas, guardar a página em que a leitura foi parada.

Os estudantes pretendem ler, estudar e fazer anotações no LDD, porém este não suporta estas ações com a facilidade desejada e requerida, principalmente se levar em conta a experiência prévia que os estudantes têm com smartphones, games e livros digitais, cuja facilidade de uso supera o LDD analisado, assim, a satisfação inicial do usuário é baixa, pois existe uma expectativa de que seja fácil de usar e incorpore recursos presentes em outros produtos digitais.

Os critérios utilizados na avaliação da usabilidade e navegação mostram-se inadequados por não levarem em conta os aspectos didáticos e objetivos educacionais, diferente de uma página de empresa ou rede social que visa o engajamento com outros fins, como a participação, fidelização, entretenimento ou compra de produtos e serviços.

O LDD analisado não permite que o usuário interaja ativamente com o conteúdo, não há links clicáveis. O item "Quer saber mais" poderia fornecer links clicáveis para acessar as páginas web recomendadas ou sugerir a busca online das outras sugestões. Desta forma, poderia estimular o interesse e a participação mais ativa dos estudantes. Algumas limitações são compreensíveis, considerando que nem sempre há acesso à internet na sala de aula e quando há, pode ser uma fonte de distrações em relação ao conteúdo do livro. Porém, quando se está online, em casa por exemplo, perde-se a oportunidade de aprofundar e ampliar o conteúdo.

A navegação é balanceada, consistente e indica claramente onde o leitor está, desta forma contribui para fornecer uma boa experiência ao estudante. As diretrizes em relação ao layout de cores e tipos são adequadas e deixam o livro agradável. As imagens são bem escolhidas, coloridas, com boa resolução, atraentes e ilustram a obra, entretanto, são estáticas e não oferecem a possibilidade de serem ampliadas ou diminuídas.

A qualidade estético funcional do projeto gráfico pode ser aprimorada, uma vez que a maioria das páginas possui muito texto e margens pequenas, causando poluição visual, sensação de desconforto $16^{\circ}$ Ergodesign - Congresso Internacional de Ergonomia e Usabilidade de Interfaces Humano Tecnológica: Produto, Informações Ambientes Construídos e Transporte

$16^{\circ}$ USIHC - Congresso Internacional de Ergonomia e Usabilidade de Interfaces Humano Computador

CINAHPA | 2017 - Congresso Internacional de Ambientes Hipermídia para Aprendizagem.

e cansaço para os olhos. O LDD poderia ser composto com simplicidade e eficiência, agregando recursos tecnológicos típicos de outros produtos digitais, como os livros digitais sem finalidade didática.

O conteúdo do livro didático é desenvolvido de modo a contemplar as proposições dos Parâmetros Curriculares Nacionais (PCN), neste sentido, o LDD pode incorporar recursos hipermidiáticos que atendam o que é preconizado pelos PCN, de modo a contextualizar diferentes formas de desenvolver e expressar o pensamento e a linguagem.

O processo de desenvolvimento de um LDD deve contar com a interação de todos os envolvidos, tanto no aspecto técnico (autor, designer, revisor e outros profissionais), quanto no aspecto pedagógico (professor e aluno). Deve haver uma preocupação ao inserir o conteúdo e recursos (como ampliar imagens, links clicáveis, gráficos, animação, áudio, simulações) que possibilitem o aproveitamento das potencialidades do ambiente digital.

Critérios de design de interação devem ser considerados para ampliar a eficácia educacional e aproveitar a experiência que os estudantes trazem da utilização de smartphones e games. Os critérios e recomendações para páginas web podem ser aplicadas ao LDD, desde que sejam consideradas suas especificidades.

A compreensão das características do LDD colabora para gerar novas abordagens no seu desenvolvimento, em especial na inserção de recursos que facilitem e tornem mais dinâmica e agradável a experiência dos estudantes com os materiais digitais, de modo a contribuir para a aprendizagem e disseminação de conhecimentos.

\section{Considerações finais}

Esta pesquisa buscou oferecer contribuições para o desenvolvimento do LDD, enfatizando a interface, porém, é importante a participação de uma equipe de desenvolvimento multidisciplinar, que ajude o autor a desenvolver livros que ofereçam, além de conteúdo de qualidade também uma experiência agradável aos estudantes. E assim, assegurar que 


\section{$16^{\circ}$ \\ ERGODESIGN USIHC CINAHPA}

$16^{\circ}$ Ergodesign - Congresso Internacional de Ergonomia e Usabilidade de Interfaces Humano Tecnológica: Produto, Informações Ambientes Construídos e Transporte

$16^{\circ}$ USIHC - Congresso Internacional de Ergonomia e Usabilidade de Interfaces Humano Computador

CINAHPA | 2017 - Congresso Internacional de Ambientes Hipermídia para Aprendizagem. os objetivos pedagógicos, lúdicos e técnicos sejam atingidos e o LDD seja um recurso melhor utilizado na escola.

A maioria dos critérios e diretrizes de interface, usabilidade e navegação foram criados para o desenvolvimento de páginas web e estão sendo adaptadas a outros produtos e sistemas. Neste sentido, priorizam questões relacionadas ao contexto do qual se originaram. Considerando as características específicas e a finalidade didática do LDD, é fundamental propor critérios voltados às questões pedagógicas. Esta é uma linha que pretende-se abordar em estudos futuros.

Outra possibilidade, é o estudo das conexões entre o game educativo e o LDD, uma vez que a atual geração de estudantes utiliza dispositivos digitais no cotidiano, com ênfase nos games. Também é necessário estabelecer critérios de análise para que o professor possa escolher um LDD para utilizar com seus alunos, de forma a atender seus objetivos pedagógicos e oferecer recursos que despertem o interesse do estudante pelos conteúdos educacionais.

Há ainda a acessibilidade, não abordada aqui, como uma oportunidade para trabalhos futuros, visto que um dos potenciais da tecnologia digital é favorecer a inserção de recursos que facilitem o uso para todos os usuários.

Considerando que a interface e a navegação devem ser invisíveis para o leitor/usuário, pode se afirmar que o LDD analisado necessita melhorar nestes quesitos, de forma a facilitar o uso, o aprendizado da navegação e oferecer uma interface mais atraente e intuitiva. Para cumprir sua função como material didático, o LDD deve garantir os resultados para os quais foi projetado, levando em consideração as características e necessidades do estudante e a finalidade pedagógica.

O cuidado em desenvolver uma navegação eficiente, intuitiva e baseada no usuário determina o sucesso de uma plataforma, juntando a isto questões visuais e aspectos cognitivos, como a forma de organizar e perceber as informações, pode se desenvolver um LDD mais agradável e de fácil utilização. Estes aspectos dizem respeito ao trabalho desenvolvido pelo designer, em estreita colaboração com os demais profissionais que trabalham em todo o processo de desenvolvimento do LDD.

O LDD analisado mostra que a complexidade do livro didático, abordada na problemática, pode ser considerada um entrave para o melhor aproveitamento dos recursos do meio digital, o que não ocorre com o livro digital em geral e o livro digital infantil em particular, os quais conseguem tirar proveito das potencialidades deste meio. Em termos de interface, usabilidade e navegação os livros digitais não-didáticos, os games e páginas web evoluíram e estão na Web 2.0, enquanto o LDD continua na geração anterior, preso aos ditames do livro impresso.

\section{Referências Bibliográficas}

\section{ASSOCIAÇÃO BRASILEIRA DE NORMAS}

TÉCNICAS NBR 9241: Ergonomia da interação humano-sistema. Parte 11: orientações sobre usabilidade. Rio de Janeiro, 2011.

BRASIL. Ministério da Educação. Programa Nacional do Livro Didático 2015. Edital de convocação para o processo de inscrição e avaliação de obras didáticas para o PNLD 2015. Brasília: 2013. Disponível em: http://www.fnde.gov.br/programas/livrodidatico/livro-didatico-editais/item/4032-pnld2015. Acesso em: 05/02/16.

BITTENCOURT, Circe M. F. Ensino de História: fundamentos e métodos. São Paulo: Cortez, 2005.

CANAVILHAS, João. (org.). Webjornalismo: 7 caraterísticas que marcam a diferença. Covilhã: Universidade da Beira Interior, 2014. Disponível em: http://www.livroslabcom.ubi.pt/book/121. Acesso em: 05/11/16.

CHOPPIN, Alain. História dos livros e das edições didáticas: sobre o estado da arte. In: Educação e Pesquisa, São Paulo, v. 30, n.3, set./dez. 2004. pp. 549-566.

COELHO, L. A. L. (Org). Conceitos-chave em design. Rio de Janeiro: Ed. PUC-Rio; Novas Ideias, 2008.

DE SOUZA, C. S. et al. Projeto de Interfaces de 


\section{$16^{\circ}$ \\ ERGODESIGN USIHC CINAHPA}

Usuário: perspectivas cognitivas e semióticas. Anais da Jornada de Atualização em Informática, XIX Congresso da Sociedade Brasileira de Computação. Rio de Janeiro, julho de 1999.

GUIA LIVRES. Livros escolares brasileiros (18102005). São Paulo. Faculdade de Educação.

Universidade de São Paulo, 2005.

KALBACH, James. Design de navegação web. Otimizando a experiência do usuário. Porto Alegre: Bookman, 2009.

KANASHIRO, Cintia S. Livro didático: discussão na perspectiva de vertentes de análise e compreensão da natureza complexa. In: Congresso Brasileiro de Ciências da Comunicação, 29, 2006, Brasília. Anais... São Paulo: Intercom, 2006.

MANOVICH, Lev. Novas mídias como tecnologia e ideia: dez definições. In: Lucia Leão (org.). O chip e o caleidoscópio: reflexões sobre as novas mídias. São Paulo: Editora SENAC, 2005.

MUNAKATA, Kazumi. O livro didático como mercadoria. ProPosições, Campinas, v. 23, n. 3, p. 51-66, Dec. 2012. Disponível em:

$<$ http://www.scielo.br/scielo.php?

script=sci_arttext\&pid=S0103-

$73072012000300004 \& \operatorname{lng}=\mathrm{en} \& \mathrm{nrm}=\mathrm{iso}>$. Acesso em: 15 jan. 2017. dx.doi.org/10.1590/S010373072012000300004 .

OLIVEIRA, Danusa de. Novos aspectos da navegação e construção do livro eletrônico. In: $2^{\circ}$ CONGRESSO INTERNACIONAL CBL DO LIVRO DIGITAL. São Paulo: CBL, 2011.

PORTUGAL, Cristina. Design, educação e tecnologia (online). Rio de Janeiro: Rio Books, 2013. Disponível em: $<$ www.design-educacaotecnologia.com>. Acesso em: 10 out. 2016.

PREECE, Jennifer; ROGERS, Yvone; SHARP, Helen. Design de Interação: Além da Interação humano-computador. 3. ed. Porto Alegre: Bookman, 2013.

ROSA, F. G. M. G. Os primórdios da inserção do livro no Brasil. In PORTO, CM., org. Difusão e cultura científica: alguns recortes [online]. Salvador: EDUFBA, 2009. pp. 75-92. ISBN 97885-2320-912-4. Available from SciELO Books $16^{\circ}$ Ergodesign - Congresso Internacional de Ergonomia e Usabilidade de Interfaces Humano Tecnológica: Produto, Informações Ambientes Construídos e Transporte

$16^{\circ}$ USIHC - Congresso Internacional de Ergonomia e Usabilidade de Interfaces Humano Computador

CINAHPA | 2017 - Congresso Internacional de Ambientes Hipermídia para Aprendizagem.

$<\mathrm{http}: / /$ books.scielo.org $>$.

SANTAELLA, L. Comunicação ubíqua:

Repercussões na cultura e na educação. São Paulo: Paulus, 2013.

SANTAELLA, L. Linguagens líquidas na era da mobilidade. São Paulo: Paulus, 2007. 